their bulk and the cost of transit. Within the past few years we have seen great iron and steel works moved from the Midlands and transported to the coast.
The railways, in spite of all the advantages they ofonly under the cheaper conditions of ocean transit that they could live. When the prices of cotton goods fell, Manchester found the cost of 36 miles of railway spent millions on a ship canal. From the same city the historical works of Sharp, Stewari \& Co. were re. tions, among which reduction of carriage expeuses was a most important item. Hence we see that not only formerly, but also to.day, people who have to earu but where they can thrive the most. Hence we understand how it was that towns grew so slowly
the railway arose to alter our social conditions the railway arose to alter our social conditions.
Modern cities are absolutely dependent on the motive for their existence from week to week, and it really seens as if some of them were so large that they were driven to London, to be there slaughtered, but one shrinks from picturing the state of our roads if have long since ceased to grow. As the town stretches outward into the country, streets multiply, but main avenues remain much as they were at the beginning
of the century. The railways carry the increased traffic, and if they were abolished, the first thing to be done would be to build roads to replace them. But
even were all done that is possible to replace the railroad and the locomotive, the removal from other transportation, and the immense rise in price of all heavy or bulky materials, would, as we have pointed out, so transform our social conditions that we should have to give up the rreater oart of what we regard
as the pleasant side of life. One does not need to be very old to notice the great change that has come
over the habits of the middle and the lower middle classes. What fifty years ayo were luxuries are now
necessities, while the necessities of those days are re

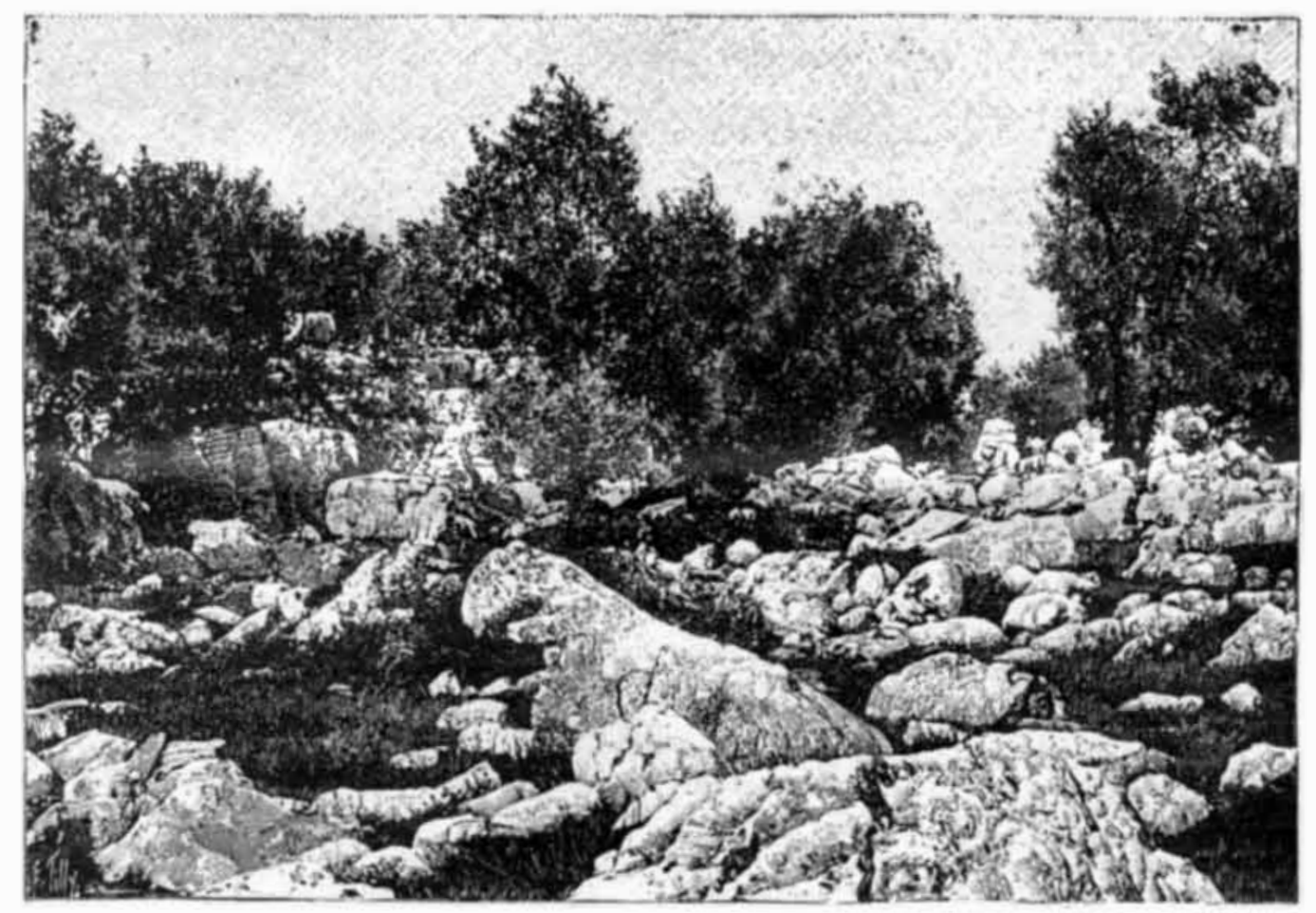

ROCK IN THE FORM OF A TIGER, SITUATED IN THE WUODS OF PAIOLIVE.

garded as only endurable under the stress of the
direst poverty. If we search the very meager accounts the historians provide of the manners of the middle ages, we encounter a picture of dirt and discomfort
which is absolutely revolting to us. The alteration from the former state of things to the present is almost entirely due to the locomotive and the railway, parin sub-tropical regions life is easier. Clothing and shelter are only required in a very moderate degree,
while the soil gives its harvest without much labor on the part of the husbandman. It was under these and the enforced labor of captive racessful conquest, The steam railway is, as we have said, the greatest labor-saving machine that the world has ever seen. If it were only that, it would still excite our admira-
tion. and its inventors and builders would deserve our gratitude. But its effects in the moral and intellectual world probably exceed those in material affairs. Just as people bred in a city differ from their consins of the country, so do the inhabitants of a developed land stand out in comparison with one that stilldepends on
the wagon and the stage coach for its transport. To find on one's breakfast table the replies to letters ad-
dressed only twenty-four hours previously to corredressed only twenty-four hours previously to corre-
spondents 400 miles away; to be able to enjoy the exhilaration of tearingithrough the country at the rate of $40 \mathrm{or}$ 50 miles an hour; to be able to travel from London to Vi-
enna in less than two days; all these are mental stimenna in less than two days; all these are mental stim-
uli that infallibly show their effect on a population, and cause it to live at a higher rate-to take more out
of time-than is possible when one must either remain in one spot or Ispend a good part of life in getting and it is only a small part that we can spend as we please. The major portion is mortgaged beforehand for food and clothing. What we can get out of the re-
mainder in the way of knowledge, experience, and widened views of the world and man depends very
much on the facilities we have for locomotion. Not only have we the benefit of what we gather ourselves in this way, but we also share in the gleanings of oth- media.te dissemination. The increase in labor-saving
ments devices has set at liberty great numbers of men who
are able to devote themselves to intellectual pursuits, Their writings, instead of passing slowly and fitfully through a small circle of readers, flash over the world and are accessible to all. We remember once review. ng a book in which the author ascribed the theory of
evolution to the express train, because, he argued,
without our modern system of railways it would have without our modern system of railways it would have
been impossible to gather cogether the immense mass facts necessary to justify the y indebted to the rail way as is the engine driver, who, but for the locomotive, would have had to gain
his living by carrying heavy burdens on his shoulders, instead of merely watching a steam motor do his work In concluding, it is sad to have to confess that while the railway has given to the bulk of us easier lives and more time for intellectual enjoyment, we have not
been able to overtop the mental stature of those that went before us. We suppose that there are now in
this country a hundred poets and dramatists for every one in the time of Elizabeth, but how much more worth are the writings of the few than of the many! Our
artists, again, have the run of all the galleries of Europe, and can compare the styles of all ages, but surope, and can compare the styles of all ages, but e bounds of a petty Italian state, are beyond their ali these things we must confess our inferiority. ven in science, which is our strong point, Newton, above us. Great men cannot be made by machinery, and, indeed, it seems as if our modern system were
antagonistic to their growth. The average man gains immensely by having a vast amount of information
placed at his command, and by being able to enter 政 seems to suffer. His relative mental stature is, of

ctual size does not come up to that of the giants of

In all professions we find it admitted that the places of the great men of the early part of the centurv are
not filled again. The average knowledge and ability of the members is immensely raised, and capable men can be counted in dnzens where once they were to be enumerated in twos and threes. But it is seldom that we find any that stand apart from their class, on a
distinct plane, as was once the case Our modern imdistinct plane, as was once the case. Our modern im-
proved methods, according to which knowledge is proved methods, according to which knowledge is
treated as a raw material by mechanical methods, and is then administered like physic. is enormously sucthe influences which are typically represented by the locomotive tend to repression. The role of machinery
is to duplicate existing objects; creation is beyond its

\section{ROCK SIMULATING A TIGER.}

The photograph reproduced herewith was taken in in the form of a tiger lying upon its belly with the forelegs extended. It is in the midst of a locality in which rocks abound, which contains many cur
things, and which is but little visited.-La Nature.

PREPARATION AND PROPERTIES OF PURE MELTED MOI.YBDENUM. By Henri Moissan.

IN a former paper we have shown that it is easy to roduce cast molybdenum, by heating in the electric furnace a mixture of charcoal and of the oxicies of this
metal. We shall now give the continuation of our reWe

We tained in a pulverulent state by the reduction of the blowpipe only in the form of small globules containing to 5 per cent. of carbon.

To prepare molybdenum we set out from pure ammo-
ium niolybdate, reduced to powder and placed in cracible of refractory earth, No. 12, capable of conheated for one and a half hours in a Perrot furnace After cooling, the oxide is a dense powder of a violet gray, corresponding to the formula $\mathrm{MoO}_{2}$. One heatwhereal, in powder, in the following proportions :

Oxide.......

300 grammes

In this mixture the oxide is in decided excess compared with the charcoal. The powder is heaped up in for six minutes. We must avoid the complete fusion of the metal, so as to leave a solid laser in contact with
the crucible which would be strongly attacked by the liquid molybdenum. Under these conditions we obtain a metal perfectly pure and free from carbon; it is easy in one hour to prepare more than 1 kilo.

If this preparation lasts more than six minutes, the ble metal, very hard and brittle.
mether

CAST MOLYBDENOM.

This cast metal has a specific gravity of 8.6 to 8.9 , rated with carbon it is nuch more fusible than molyb-
denum. When rich in carbon it is gray and brittle; at 12.5 per cent. of carbon it becomes white. and can be
broken up upon the anvil only with difficulty. It presents all the characteristics of the molybdenuro stu-
died by Debray. It rapidly dissolves carbon, and died by Debray. It rapidly dissolves carbon, and cisely as does cast iron. Nevertheless, when saturated with carbon it yields a carbide, crystallized in fine needles. Gray cast molybdenum is very hard; it
scratches steel and quartz. When melted, it becomes very uobile liquid, which can be poured while giv ing bright sparks and abundant fumes of molybdic from 8 to 10 kilos. These castings had the following compositions:

\begin{tabular}{|c|c|c|}
\hline & Wh & \\
\hline $\begin{array}{l}\text { Molybodenum } \ldots \ldots \\
\text { Gombined carbon. } \\
\text { Grapbite.......... } \\
\text { Slags ............. }\end{array}$ & $\begin{array}{l}95 \cdot 83 \\
3 \cdot 04,3 \cdot 19,2 \cdot 54 \\
0 \cdot 00 \\
0 \cdot 74,0 \cdot 53,0 \cdot 62\end{array}$ & $\begin{array}{l}92 \cdot 46 \\
4 \cdot 90,5 \cdot 50 \\
0 \cdot 00,1 \cdot 71 \\
-\quad-\end{array}$ \\
\hline
\end{tabular}

This compound is prepared by heating in the electric furnace molybdenum binoxide with an excess of grammes; charcoal, 50 granmes. The duration of the 800 amperes and 50 volts. If we use an excess of 800 amperes and 50 volts. If we use an excess of
charcoal, it is found in the mass in the state of graph-

ite The regulus obtained is of brilliant white and has a crystalline fracture; it splits readily. It is readily crushed on the anvil, and we may separate from it small elongated prisms of a distinet erystallization.
Its suecific gravity is 8.9 , and its composition is $\mathrm{Mo}_{2} \mathrm{C}$. ANALYSIS.

In the various specimens described in this memoir, the molybdenum, after treatment with nitric acid, has been precipitated as mercurous moly bdate, and finally graphite, the carbon was separated by pure dry chlorine, aud then determined by combustion in oxygen, aceonding to the weight of carbonic acid collected.
According to this method, the portions of carbon are We have obtained the following figures:
Weys rather low.

$$
\begin{aligned}
& \begin{array}{ccccc}
\text { Molybdenum. ... } & 93 \cdot 82 & & & \begin{array}{r}
\text { Theory for } \\
\text { Mo }_{2} \text { C. } \\
\text { C4. }
\end{array} \\
\text { Combined carbon. } & 5 \cdot 62 & 5 \cdot 53 & 5 \cdot 48 & \begin{array}{r}
\mathbf{9 4} 12 \\
5.88
\end{array}
\end{array} \\
& \begin{array}{l}
\text { Graphite........... } \\
\text { Slags............. } \\
0 \cdot 17 \\
0 \cdot \cdot 61
\end{array}
\end{aligned}
$$

If the carbide contains graphite, it is attacked in a The gases evolved pass into a tube filled with oxygen. oxide, the watery vapor is retained in a tube filled with sulphated pumice, and the carbonic acid is fixed in potassa. The inerease of the weight of the potassa
tube shows the carbonic acid, and consequently the in washing, shows the graphite, and the molybdenum is method gave as results
Molybdenum........
$\begin{array}{rr}92 \cdot 60 & 91 \cdot 90 \\ 5 \cdot 15 & 5 \cdot 43\end{array}$
Graphite...
$161 \quad 1.98$

On taking account of the graphite and calculating fiud

$$
\begin{array}{lrr}
\text { Molybdenum........94.45 } & 94 \cdot 10 & 94 \cdot 12 \\
\text { Combined carbon....5.55 } & 5.90 & 5 \cdot 88
\end{array}
$$

PURE FUSED MOLYBDENUM.

Pure molybdenum has a specific gravity of 9.01. It is a metal as malleable as iron. It can be easily filed
and polished, and forged hot. It does not seratch either quartz or glass. When free from carbon and
silicon, it scarcely oxidizes in the air below a dull red. ness. It may be kept for severaldays unchanged in water, whether ordinary or charged with carbonic ered with an iridescent film, as is steel. About $600^{\circ}$ it begins to be oxidized, and yields molybdic acid, which is slowly volatilized.
A fragment of molybdenum heated for some hours a sloping porcelain tube over an analytical furnace ine npper part of the tube, a felted mass of with any other oxide. and finally disappears, leaving a fine crystallization of molybdic aeid. If heater before the gas blowpipe, a fraginent of molpbdenum emi1s
vapors in considerable quantity. If heated before the 
oxyhydrogen blowpipe, it burns without melting, giv- vices, because it burns rapidly upon the surface of the affected, This difficulty increases with the height

oxyhydrogen blowpipe, it burns without melting, giv-
ing off abundant fumes of molybdic acid and leaving ing off abundant fumes of molybdic acid and leaving
a blue oxide, sparingly fusible. If heated in a current
of pure oxygen, it takes fire between $500^{\circ}$ and $600^{\circ}$ of pure oxygen, it takes fire between $500^{\circ}$ and $600^{\circ}$;
and if the current is rapid, the combustion may. continue without
source of heat.

bustion ensues with intense incandescence, and may serve as a fine lecture experiment.

Melting potassium chlorate attacks molybdenum
with violence. The chlorate is nelted, and a fragment of molybdenum thrown upon its sufrace, when it be comes incandescent and revolves upon the surface of the liquid.

The temperature of the reaction rises rapidly, the molybden um burns with fame, and there escape suspended in the air in the form of white floating fila-
ments. Sometimes the fravment of molybdenum is ments. Sometimes the fragment of molybdenum is raised to a temperature high enough to perforate the
side of the capsule, which is melted in contact with side of the capsule, which is melted in contact with Me metal.
Melting potassium nitrate under similar condition formation of an alkaline molybdate. formation of an molybdenum and lead peroxide heated in a test tube produces a great liberation of heat and Sulphur has no action at $440^{\circ}$, but hydrogen sulplide at $1,200^{\circ}$ transforms molybdenum into a bluish gray denite, and leaving, on friction, a black mark upo

paper. but if the metal is coarsely powdered, there is formed without incandescence, a volatile fluoride.

Chlorine attacks molybdenum at dull redness, but without incandescence. With bromine the action takes pla

Iodine has no action at the temperature of softenin

Silver, zine and lead fluorides are decomposed, but without the formation of volatile fluoride

Thosphorus perchloride, if slightly heated, readily which is easily modified in presence of atmospheric moisture, taking a fine blue coloration.

This reaction is produced with most of the compounds of metallic molybdenum - the oxides, the sulphide, molybdic acid, and the molybdates. It may
serve for the rapid detection of metallic molybdenum serve for the rapid detection of metallic molybdenum
or its compounds. It is effected in the followin or its compounds. It is effected in the following
manner: Into a small test tube we put a fragment of the sub stance in question, adding a little phosphorus perdish fumes of molybd enum chloride and oxychloride, which condense in a brown ring more or less intense.
If the quantity of molybdenum is very slight, the ring If the quantity of molybdenum is very slight, the ring
may be scarcely visible. It will then be sufficient to
expose it to moisture to see it take an intense blue expose it to moisture to see it take an intense
tint, due to the formation of hydrated chloride.

The action of hydracids upon pure molybdenum is almost similar to that which they exert upon cast molybdenum. These experiments, however, have
been described by different observers, Bucholz, Berzebeen described by different observers, Bucholz, Berzelius and Debray. We merely mention that hydrofluoric acid does not attack it, but on adding a drop
of nitric acid the action sets in and continues with energy. In presence of a mixture of equal parts of mains a rose colored liquid which, with ferrocyanide gives an intense red brown color, but no precipitate.
The mass some hours afterward coagulates to a The mass some hours afterward coagulates to In a current of nitrogen at $1,200^{\circ}$ molybdenum whether in fragments or in powder, does not form

It does not combine

Boron combines with molybdenum at the temperature of the electric furnace, yielding an iron gray
melted mass containing cavities lined with prismati melted mass containing cavities lined with prismatic
needles. Under the same conditions, silicon yields a crys talline silicide not fusible befor the
blowpipe. The action of carbon deserves to arrest our attention for a few moments.

Pure molybdenum, as above described, is a sof metal, which is easily filed and which does not even for some hours to a temperature close on $1,500^{\circ}$ in the midst of a mass of charcoal in powder, it becomes ce mented, takes up a small quantity of carbon, and its hardness increases so that it can seratch glass. If we then heat it to $300^{\circ}$ and plunge it suddenly into col
water, it is tempered, becomes brittle, and har enough to scratch rock crystal.

Inversely, if we take cast molybdenum containing 4 per cent. of carbon, very hard and brittle, and heat a in a lined crucible, it becomes molybdenum binoxide may then be readily tiled and polished.

I attribute this decarburation of the solid cast molybdenum at a temperature very remote from it melting point to the ready diffusion of vapors of
molybdic acid through the metal. I consider that molybdic acid through the metal. 1 consider that
these properties may find applications in metallurgy.
If in metal saturated with oxygen, such as is ob. tained in the first period in the Bessemer converter, we wish to remove this oxygen, we add manganese,
which is oxidized more easily than iron, and ther passes into the slag (Troost and Hautefeuille). It has been also proposed to employ aluminum, which has
given good results, because it is combustible, i. e., begiven good results, because it is combustible, i. e, be-
cause it seizes on the oxygen, but which has the inconvenience of producing solid alumina. I think that molybdenum may be used under the same conditions

1. Of yielding a volatile oxide, molybdic acid, whic
it would would be liberated immediately in the gaseous state
stirring up the whole mass. stirring up the whole mass.
2. Used in a slight excess it would leave in the bath a metal as malleable as iron, and capable of being tempered along with the latter. The powder of molybdenum, which it has been at
tempted to use already, cannot render the same ser- vices, because it burns rapidly upon the surface of the
bath in contact with the air without having yielded any useful effect.

ANALYSIS OF PURE MOLYBDENUM.

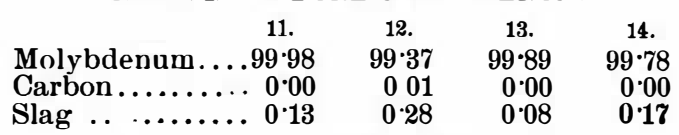

Comptes Rendus, exx, p. 1320 ; Chem. News.

[Continued from SUPPLEMENT, No. 1022, page 16341.]

THE USE OF HOT AIR IN DRYING.*

By Е. M. Соок, New York.

THe methods of handling textile fabries, etc., are carcely necessary to refer to them. Goods in considerable pieces may be stretched from side to side, or up and down, in a drying chamber, in some cases moving
automatically, the drying currents having access to automatically, the drying currents having access to
them; or they may be passed over revolving heated surfaces, as in the well-known form of paper machine.
In handling materials in lumps, grains, or powder, the problem is more difficult, and, apart from revolving cylinders or fixed cylinders with revolving stirring de-
vices, there are but few devices in practical operation. vices, there are but few devices in practical operation. conducting surfaces: and, although air is sonetimes used as an accessory, they are not really hot-air driers. By far the most efficient device for moving material consists of a series of superposed, endless aprons, having a slow, continuous motion, each alternate apron moving in opposite directions. Each apron projects material under treatment, being fed in a thin laver upon the upper one of a series, is slowly carried forward and deposited successively u pon each in turn,
and finally delivered at the bottom. The aprons are made of material suitable for the particular substance, and may be perforated; though this in ny opinion, low the lines of least resistance, which will not be through a layer of the material, however thin. To get a sufficient run, the aprons should have considerable length, and may be of such width as the weight and considerations and that of space available, the number of aprons in a drier is controlled. I have recently inspecter such an apparatus in practical operation, in subjected to a high temperature. The aprons are
eleven in number, spaced 16 in. apart vertically, and are each $50 \mathrm{ft}$. long and $6 \mathrm{ft}$. wide, giving a total
length of $550 \mathrm{ft}$. They move at a speed of $150 \mathrm{ft}$. per length of $550 \mathrm{ft}$. They move at a speed of $150 \mathrm{ft}$. per
hour, the substance being retained in the drier nearly four hours. They are made of cotton cloth, inclosed by a fan blower over steam coils. The air enters at about $195^{\circ}$, and is discharged at about $135^{\circ}$. Its humidity at discharge is not measured, but from these figures, even making no allowance ior losses by
radiation, etc., its saturation cannot exceed about 0.18. Obviously this is not an economical appli. water, this may be of minor importance. The apparatus is considered a fairly satisfactory one, but there ing system, both its economy and efficiency would be Another drier of this kind is also in use in Brooklyn, N. Y., for drying brewer' grains. This material car-
ries fresh from the mash tub from 75 to 80 per cent. of water. As the saturating liquor carries in solution a be pressed without sacrifice. It constitutes, when dry, a food of high economical and commercial value for cows and horses; the experiments of the New Jersey
Agricultural Experiment Station show that for the Agricultural Experiment Station show that for the pound for pound. As a food for cows it is largely use wet; but, as it is subject to rapid fermentation and
decomposition, in which condition the milk produced from it is exceedingly undesirable as a food, most of with it in that condition, and, in consequence much of it produced in summer, especially in the large It is obvious that with so large an amount of wat to eliminate, and the comparatively low value of the dried grains, utmost economy in drying is im perative. The apparatus in question is on a large scale, having a capacity of about 150 bishels of wet grains per hour,
which should produce something more than $2,000 \mathrm{lb}$ dry; this would require the evaporation per twentyAmerica) of water. It consists of ten aprons, each 12 ft. wide by $50 \mathrm{it}$. long, spaced about 24 in. apart, and contained in a substantial brick structure nearly 30 ft. high. The aprons are of wire cloth, varying from
the uppermost to the lowest apron of the series, from 8 to 14 meshes to the inch. The motion is at the rate of 6 to $8 \mathrm{ft}$. per minute, giving from 75 to 90 minutes fer in a very thin layer upon the uppermost apron. fed in a very thin layer upon the uppermost apron. tion chamber, are admitted to the drier at tempera-
tures which, perhaps, vary at the different openings tures which, perhaps, vary at the different opening
of communications, but was said not to exceed $300^{\circ}$ of communications, but was said not to exceed 300 The discharge temperature varies under different consphere, but was said to average $160^{\circ}$ to $170^{\circ}$; this indicates a low degree of saturation.

But in any attempt to move material horizontally, for drying, unavoidable drawbacks are encountered Among the most serious of these are : First, the diffi-
culty of controlling horizontal currents of hot air in a increased by the presence of obstructions, moch stationary. It is found that the current will be prin. cipally confined to the upper part of the chaniber,
and any material near the bottom will bo but little *A paper read before the Chemical Society, London, May 6, 1895.
-From the Journal of the Soolioty. and length of the chamber, and can only be partially remedied by especially locating the positions of the
inlet and discharge openings, or by admitting air of different temperatures at different heights in the chamber. Second, the influence of the wind, which, when in an adverse direction, has a tendency to drive
the current back, causes great irregularity in the drying, and occasionally almost entirely checks it. Third, the amount of power required to keep in horizontal
motion a considerable weight of apparatus and ma-
terial; and, lastly, and by no means the least inportterial; and, lastly, and by no means the least inport-
ant where land is valuable, the large space required for driers of this clas

In a vertical chamber or flue the tendency of an out its section and the presence of obstructions favors and promotes this; also, if the chamber is of considwill materially assist its ascent, and the direction of will materially assist its ascent, and the dit
the wind will have little or no effect upon it.
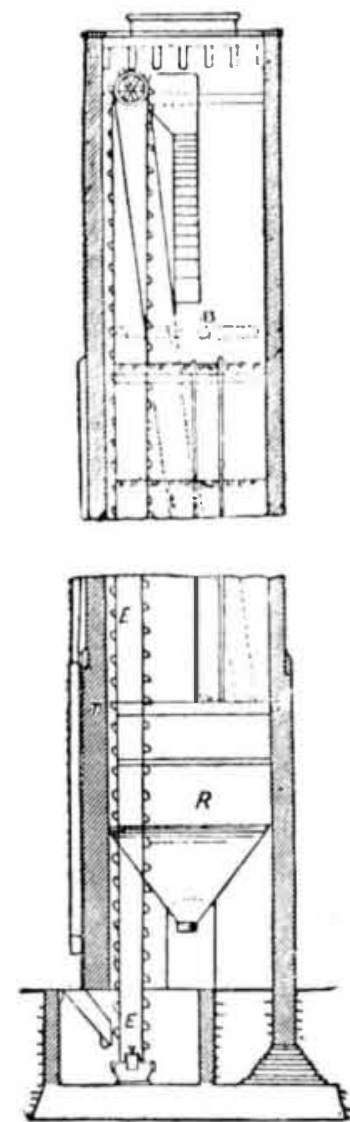

The desideratum, then, for handling granular mateial successfully is a device by which it shall be caused o descend through such a chamber, by a regulated,
methodical descent, at such a rate as shall suffice for its drying, and it must be divided into small portions, and requently turned over, to allow of access of the descend by its own weight, and as we shall only have to control or retard its descent, the power required to In

In the apparatus which I have devised and constructed for elnbodying these ideas, the containing
tower, $T$, is of brick, inclosing on the ground a space
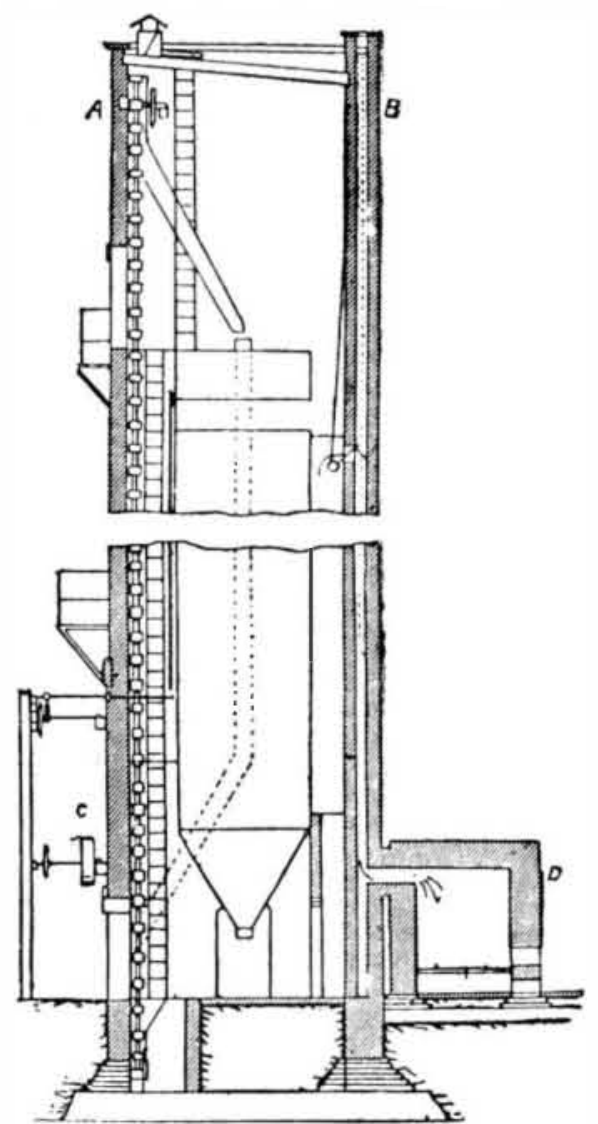

of $10 \mathrm{ft}$. by $13 \mathrm{ft}$. and is about $80 \mathrm{ft}$. $\mathrm{h}$ igh ; a considerable and perhaps unnecessary portion of the height bereceiving bin, $R$, at the bottom for the dried grains. The drying chamber proper is over $40 \mathrm{ft}$. in hoight, and rial, arranged in 60 tiers, so placed that those in each
tier break joint or alternate in position with those in the tiers above and below. These trays, $t$, shown in
the enlarged detail, are $8 \mathrm{ft}$. long, made of galvanized 